Revue

Revue de l'histoire des religions

de Ihistoire des religions

\title{
Mistici italiani dell'Età moderna, a cura di Giacomo JORI, introduzione di Carlo osSOLA
}

Torino, G. Einaudi, 2007, LX-703 p., 22 cm, (« I millenni »), $80 €$.

\section{Sophie Houdard}

\section{OpenEdition}

\section{Journals}

Édition électronique

URL : http://journals.openedition.org/rhr/7600

DOI : $10.4000 /$ rhr.7600

ISSN : 2105-2573

Éditeur

Armand Colin

Édition imprimée

Date de publication : 1 juin 2010

Pagination : 264-266

ISBN : 978-2200-92656-4

ISSN : 0035-1423

\section{Référence électronique}

Sophie Houdard, «Mistici italiani dell'Età moderna, a cura di Giacomo JoRı, introduzione di Carlo ossola », Revue de l'histoire des religions [En ligne], 2 | 2010, mis en ligne le 26 janvier 2011, consulté le 22 septembre 2020. URL : http://journals.openedition.org/rhr/7600; DOI : https://doi.org/10.4000/rhr. 7600

Ce document a été généré automatiquement le 22 septembre 2020

Tous droits réservés 


\section{Mistici italiani dell'Età moderna, a cura di Giacomo JORI, introduzione di Carlo ossolA}

Torino, G. Einaudi, 2007, LX-703 p., 22 cm, (« I millenni »), $80 €$.

\section{Sophie Houdard}

\section{RÉFÉRENCE}

Mistici italiani dell'Età moderna, a cura di Giacomo JoRI, introduzione di Carlo ossolA, Torino, G. Einaudi, 2007, LX-703 p., 22 cm, (« I millenni »), $80 €$.

1 Giacomo Jori nous offre une magnifique anthologie consacrée aux Mystiques italiens de l'époque moderne chez l'éditeur Giulio Einaudi, choisissant pour la couverture du coffret la célèbre "Madeleine en extase » du Caravage (1606). Le corps alangui, la bouche à demi ouverte et les yeux mi-clos, la sainte donne à voir un corps dont la volupté s'offre au moment même où il se soustrait dans le secret d'une âme ravie que le peintre capture dans un jeu d'ombres et de lumières mourantes. Un cahier central d'illustrations rappelle par ailleurs le rôle joué par les artistes à l'époque moderne pour représenter les phénomènes dont les corps - surtout féminins - sont l'objet : stigmates, extases, rapt, vol de l'âme, apparitions, visions. Le corps occupe en effet une place centrale dans cette anthologie de textes qui narrent les extases de Maria Maddalenna de'Pazzi, dont les religieuses-secrétaires notent par des blancs l'irruption dans les dits de la sainte, celles de Filippo Neri que fournissent les témoins pour son procès en canonisation, les stigmates de Veronica Giuliani, de Carlo da Sezze, etc.

2 Les phénomènes visibles et sensibles qui caractérisaient les "saintes vives" de la période médiévale n'ont pas déserté les corps des mystiques italiens qui prolongent au début de l'époque moderne les formes multiples de l'incorporation divine. Mais c'est au moment où, sur fond de continuité, tout change radicalement que l'anthologie s'inscrit et choisit sa perspective critique. Car les phénomènes sensibles sont toujours plus 
équivoques, voire condamnés, les écrits qui en témoignent les jugeant le plus souvent inutiles ou dangereux, et si le corps et la raison sont au centre de la connaissance amoureuse de Dieu, c'est au prix de leur soustraction, par l'anéantissement ou l'annihilation qui transforme la mystique en un secret, tout entier recelé dans un langage qui mine le processus de la représentation et des savoirs.

Giacomo Jori a choisi de réunir des écrits mystiques au moment où leur essor, voire leur triomphe (qui accompagne la naissance du substantif, la mystique) rencontre les examens et les procès qui scellent en même temps leur déclin et leur disparition dans le monde catholique. « La mystique moderne, en particulier après le concile de Trente, a cessé de vouloir purifier le monde, pour se purifier elle-même, sa manière de voir, de se nourrir de formes, pour se dépouiller, se dénuder, en se laissant polir comme tabula rasa ", écrit Carlo Ossola dans une introduction, « La parola mistica ", qui joue, comme l'indique le titre, sur la naissance et l'avenir d'un mot (la mystique) qui est aussi parole poétique. Constatant la difficulté de composer une anthologie de textes qui revendiquent la nudité de la foi et de l'expression, un langage balbutiant et rétif à la clarté des langages des rationalités modernes, Carlo Ossola revisite la naissance de la modernité littéraire depuis les formes baroques des éclairs et des instants de l'ardeur mystique jusqu'aux formes mélancoliques et abandonnées des écrits du désert oranais de Charles de Foucauld et ceux du suédois Dag Hammarskjöld. Cette introduction, rendant hommage aux travaux critiques de Jean Baruzi et de Michel de Certeau, ouvre sur les formes romanesques, poétiques, voire politiques les plus proches de nous. En puisant dans le XVII ${ }^{e}$ siècle ses premières traces et ses premières manifestations, Carlo Ossola saisit le moment où la "parole mystique » (mot, chose et forme langagière) s'émancipe de la phénoménalité pour s'ouvrir à l'excès de l'expérience mystique, comme expériences langagières soustraites.

4 Les écrits italiens de l'époque moderne sont classés ici selon quatre sections qui fournissent une quadruple voie ou quatre points de vue qui sont autant d'interprétations (au sens musical et cognitif) : Mystica experimentalis, Mystica memorialis, Theologia mystica, Poesis mystica. Les titres en latin indiquent en sous-main que la langue italienne trouve sur le socle de la Vulgate et du latin d'Église son élan pour inventer un vocabulaire spécifique qu'elle traduit et enrichit (voir l'index des lieux bibliques en fin de volume). Cette «illustration » de la mystique par la langue italienne est surtout le fait des congrégations religieuses (le Carmel de Maria Maddalena de'Pazzi, l'Oratoire de Filippo Neri, la Société de Jésus d'Achille Gagliardi, etc.) qui narrent une mystique nourrie de l'expérience de la volonté. Les femmes dominent cette première section, qu'elles soient devenues saintes, comme Maria Maddalena de'Pazzi en 1669, soupçonnées, jusqu'à devoir abjurer comme Isabella Berinzaga, simples tertiaires domnicaines et peu lettrées comme Caterina Paluzzi, ou fondatrices d'un monastère comme Giovanna Maria della Croce. Les formes de l'expérience autorisent-elles la mystique ? la mémoire écrite (deuxième section) organise la tradition moderne de ces "nouveaux saints" qu'on désigne ainsi avec soupçon. Les vies et les procès en canonisation enregistrent, éliminent, corrigent les données de la mystique expérimentale : Filippo Neri, Maria Maddalena de'Pazzi cohabitent dans la deuxième section avec Giulia di Marco que l'Inquisition condamne en 1615 pour sa luxure et son illuminisme, et d'autres propositions hétérodoxes qui mettent au jour la proximité de la mystique avec les formes de spiritualité espagnoles que Valdès a exportées à Naples et avec bien des formules prêtées à tous ceux qu'on dira bientôt quiétistes. La mémoire officielle s'efforce de canaliser les cénacles spirituels, les groupes « hors les murs » où 
survivent les courants condamnés depuis le Moyen Âge comme le Libre Esprit. Simone Leoni, condamné en 1687 par le Saint-Office, ne prône-t-il pas l'impeccabilité de l'âme, la rénovation adamique et l'indifférence à la chair selon les plus anciennes traditions ?

5 La section suivante - Theologia mystica - qui est aussi la plus longue, est celle des hommes d'Église dont l'entreprise est d'encadrer, normer, sinon normaliser, la doctrine mystique. La contemplation, les formes de l'oraison (infuse ou acquise), les moyens de discerner d'où vient l'esprit et de diriger l'âme sont au cœur des traités, mais les procès du quiétisme italien emportent Giovanni Maria Gramaldi, Pier Matteo Petrucci et Thomaso Menghini. La dernière section permet d'ouvrir sur le refuge poétique de la mystique, à l'ombre de la grande tradition de poésie claustrale, qui s'ouvre aux formes profanes de la poésie (madrigal, sonnet, chanson) et aux inventions langagières pour que la doctrine se laisse dès lors chanter et parler.

Chaque auteur donne lieu à une courte note bio-bibliographique, ce qui permet de suivre sans difficulté ce quadruple éclairage. On en donnera un seul exemple : San Carlo Sezze a été poète, théologien de la vie spirituelle, doté d'extases et de stigmates; le jésuite Achile Gagliardi a suivi Isabella Berinzaga dans sa vie expérimentale, avant de rédiger le Breve Compendio di perfezione cristiana dont la première édition, dès la fin du $\mathrm{XVI}^{\mathrm{e}}$, est donnée dans une traduction française: les sections de l'anthologie sont heureusement poreuses et Giacomo Jori laisse migrer les mystiques italiens d'une section à l'autre. Ce n'est pas l'une des moindres qualités de ce recueil que de nous amener à suivre les "essais » des mystiques, leurs inventions, leurs efforts et leurs échecs pour créer au début de l'époque moderne une littérature, une tradition et un langage.

\section{AUTEURS}

\section{SOPHIE HOUDARD}

Université Paris III - Sorbonne Nouvelle. 